\title{
Analisis Faktor-faktor yang Memengaruhi Penyaluran Kredit Perbankan (Studi pada Bank Umum Milik Negara)
}

\author{
Sita Nurmalia Adha \\ Perbanas Institute \\ Hedwigis Esti Riwayati \\ Perbanas Institute \\ hedwigis.esti@perbanas.id
}

\begin{abstract}
Abstrak
Penelitian ini bertujuan untuk menganalisis pengaruh Capital Adequacy Ratio, Non Performing Loan, dan Suku Bunga Sertifikat Bank Indonesia terhadap Penyaluran Kredit Perbankan. Data yang digunakan dalam penelitian ini adalah data sekunder berupa data triwulanan kredit, Capital Adequacy Ratio, Non Performing Loan, dan Suku Bunga Sertifikat Bank Indonesia yang diperoleh dari publikasi website Bank Indonesia dan Otoritas Jasa Keuangan. Teknik pengumpulan sampel yang digunakan dalam penelitian ini dengan metode sampling jenuh. Metode analisis data yang digunakan adalah analisis statistik deskriptif dan analisis regresi data panel dengan menggunakan alat bantu pengolahan data yaitu program Eviews 8.0 for windows. Pengujian hipotesis menggunakan uji hipotesis parsial (uji t), uji goodness of fit (uji F), dan koefisien determinasi dengan tingkat signifikansi 5 persen. Hasil penelitian menunjukkan bahwa variabel capital adequacy ratio dan suku bunga sertifikat bank indonesia berpengaruh positif dan signifikan terhadap penyaluran kredit sedangkan variabel non performing loan berpengaruh negatif dan signifikan terhadap penyaluran kredit. Model dalam penelitian ini layak untuk menjelaskan penyaluran kredit perbankan pada Bank BUMN. Penelitian ini diharapkan dapat menambah referensi di bidang yang berkaitan dengan penyaluran kredit. Serta hasil penelitian ini diharapkan dapat memberikan kontribusi yang baik serta dapat mengembangkan wawasan masyarakat tentang penyaluran kredit bank. Peneliti selanjutnya dengan topik yang sejenis diharapkan dapat menambah variabel bebas lainnya yang diperkirakan berpengaruh terhadap penyaluran kredit seperti DPK, LDR dan variabel makro seperti inflasi.
\end{abstract}

Kata Kunci: Penyaluran Kredit, Capital Adequacy Ratio, Non Performing Loan dan Suku Bunga Sertifikat Bank Indonesia.

\section{Pendahuluan}

Bank yang berprestasi atau berpredikat sangat bagus dilihat dari kinerja keuangan bank tersebut. Perbankan harus memiliki kinerja keuangan yang sehat dan efisien agar mendapatkan keuntungan atau laba. Bank sebagai intermediasi antara debitur dan kreditur memiliki kewajiban penuh untuk menjaga "kepercayaan" yang diberikan oleh nasabahnya. Bank perlu menjaga citra positif di mata masyarakat untuk menjaga dan meningkatkan kepercayaan nasabah. Citra ini dapat dirasakan dari pelayanan yang diberikan oleh pihak perbankan terhadap nasabah. Kegiatan penyaluran kredit adalah rangkaian kegiatan intermediasi utama perbankan dimana penyaluran kredit merupakan tulang punggung kegiatan suatu bank 
(Putra dan Rustariyuni 2015). Pertumbuhan kredit yang baik dapat membantu mensejahterakan masyarakat banyak karena dari dana yang bersumber dari masyarakat merupakan sumber dana pokok yang dimiliki oleh bank. Aktivitas perbankan yang pertama adalah menghimpun dana dari masyarakat, dana tersebut berasal dari kegiatan bank yang dikenal dengan istilah funding, menghimpun dana artinya mengumpulkan atau mencari dana dengan cara membeli dari masyarakat luas (Riyadi 2017). Pembelian dana dari masyarakat ini dilakukan oleh bank dengan cara pemasangan strategi agar masyarakat mau menanamkan dananya dalam bentuk simpanan. Kegiatan funding ini berupa giro, tabungan, sertifikat deposito dan deposito. Kegiatan bank menyalurkan dana kembali kepada masyarakat yang dikenal dengan istilah kredit (lending). Penyaluran kredit bank harus bisa menghasilkan keuntungan, membantu nasabah dan membantu pemerintah. Penentuan kualitas suatu kredit perlu diberikan ukuran-ukuran tertentu, sehingga kolektibilitas kredit digolongkan menjadi 5 bagian diantaranya: kredit lancar, kredit dalam perhatian khusus, kredit kurang lancar, kredit diragukan, dan kredit macet. Penyaluran kredit tidak mudah diberikan begitu saja kepada nasabah, bank harus mengetahui informasi nasabah tersebut bermasalah atau tidak kepada bank lain, karena jika debitur tersebut bermasalah maka penyaluran kredit perlu dihindari supaya tidak terjadi kredit macet atau hal-hal yang tidak diinginkan. Sebelum kredit diberikan, maka bank terlebih dulu harus mengadakan analisis kredit untuk meyakinkan bahwa nasabah benar-benar dapat dipercaya. Pemberian kredit tanpa analisis terlebih dahulu akan sangat membahayakan bank (Kasmir 2016). Jika kredit yang disalurkan mengalami kemacetan, maka langkah yang dilakukan untuk penyelamatan harus dilihat terlebih dahulu penyebabnya. Pihak bank perlu melakukan penyelamatan agar tidak menimbulkan kerugian, penyelamatan yang dilakukan bisa dengan cara memberikan keringanan jangka waktunya. Kredit yang disalurkan harus mendapatkan laba yang optimal serta menjaga keamanan atas dana yang dipercayakan nasabah penyimpan dana. Penyaluran kredit perbankan dapat dipengaruhi oleh faktor eksternal maupun internal bank (Kasmir 2016). Rasio keuangan yang digunakan dalam penyaluran kredit yaitu Capital Adequacy Ratio (CAR), Non Performing Loan (NPL), dan Suku Bunga Sertifikat Bank Indonesia (SBI). Penyaluran kredit tersebut menggunakan rasio keuangan yang disajikan melalui laporan keuangan perusahaan yang diterbitkan setiap tahunnya.

Pengendalian kredit harus dilakukan untuk menghindari terjadinya kredit bermasalah. Pengendalian tersebut dapat dilakukan melalui pengawasan langsung, tidak langsung maupun kombinasi keduanya. Pemberian kredit harus dilakukan dengan pengendalian yang baik dan benar serta memegang prinsip kehati-hatian. Bank biasanya memiliki kriteria-kriteria serta aspek penilaian terhadap calon nasabah yang akan menerima fasilitas kredit. Inflasi akan mempengaruhi tingkat suku bunga SBI, selanjutnya suku bunga SBI akan mempengaruhi kondisi internal bank. Ketika naiknya suku bunga SBI akan menyebabkan naiknya suku bunga deposito, suku bunga tabungan. Kenaikan suku bunga deposito akan berpengaruh terhadap suku bunga kredit. Penurunan suku bunga kredit juga akan menurunkan biaya modal perusahaan untuk melakukan investasi. Menurut PBI No. 4/10/PBI/2002 tentang Sertifikat Bank Indonesia, SBI adalah surat berharga dalam mata uang Rupiah yang diterbitkan oleh Bank Indonesia sebagai pengakuan utang berjangka waktu pendek. Tingkat suku bunga ini ditentukan oleh mekanisme pasar berdasarkan sistem lelang. Upaya Bank Indonesia untuk menurunkan BI rate dengan harapan agar suku bunga kredit turun akan menggairahkan investasi. Bank Indonesia pada umumnya akan menaikkan BiI rate apabila inflasi ke depan akan diperkirakan melampaui sasaran yang telah ditetapkan, sebaliknya Bank Indonesia akan menurunkan BI rate apabila inflasi ke depan diperkirakan berada di bawah sasaran yang telah ditetapkan. Penyaluran kredit dipengaruhi oleh faktor internal dan eksternal bank. Faktor 
internal yang digunakan dalam penelitian ini yaitu Capital Adequacy Ratio (CAR), dan Non Performing Loan (NPL). Sedangkan faktor eksternal yang digunakan sebagai variabel penelitan adalah Suku Bunga Sertifikat Bank Indonesia (SBI).

Semakin tinggi nilai Capital Adequacy Ratio (CAR) berarti semakin tinggi modal sendiri untuk membiayai aktiva produktif dan semakin rendah biaya yang dikeluarkan oleh bank (Kasmir 2016). Capital Adequacy Ratio (CAR) berpengaruh positif signifikan terhadap penyaluran kredit (Oktaviani 2012). Berbeda dengan hasil penelitian (Sari 2013) diperoleh hasil bahwa Capital Adequacy Ratio (CAR) berpengaruh negatif signifikan terhadap penyaluran kredit.

Pengaruh NPL terhadap penyaluran kredit pernah diteliti oleh ( Sari 2013; Putra dan Wirathi 2014; Aljufri dan Onasis 2015) yang menunjukkan bahwa Non Performing Loan (NPL) berpengaruh negatif signifikan terhadap penyaluran kredit. Semakin tinggi tingkat Non Performing Loan (NPL) akan menurunkan jumlah kredit yang disalurkan. Sedangkan penelitian yang dilakukan oleh (Putra dan Rustariyuni 2015) Non Performing Loan (NPL) berpengaruh positif signifikan terhadap penyaluran kredit.

Faktor lain yang bisa mempengaruhi penyaluran kredit perbankan adalah suku bunga SBI. Semakin tinggi suku bunga SBI akan meningkatkan jumlah kredit perbankan yang disalurkan tetapi memberikan dampak secara berkala (Apsari 2015). Panggalih (2015) menyatakan bahwa suku bunga Sertifikat Bank Indonesia (SBI) berpengaruh positif signifikan terhadap penyaluran kredit. Berbeda dengan (Oktaviani 2012), yang menyatakan bahwa suku bunga Sertifikat Bank Indonesia (SBI) berpengaruh negatif signifikan terhadap penyaluran kredit. Berdasarkan latar belakang di atas, maka peneliti terdorong untuk menganalisis pengaruh Capital Adequacy Ratio, Non Performing Loan dan suku bunga Sertifikat Bank Indonesia terhadap penyaluran kredit pada Bank Umum Milik Negara.

\section{Landasan Teori dan Pengembangan Hipotesis}

Salah satu komponen faktor permodalan di bank adalah kecukupan modal (Riyadi 2017). Rasio untuk menguji kecukupan modal bank yaitu rasio Capital Adequacy Ratio (CAR). Menurut (Kasmir 2016) Capital Adequacy Ratio (CAR) merupakan rasio kewajiban pemenuhan modal minimum yang harus dimiliki oleh bank. Untuk saat ini minimal CAR sebesar 8 persen dari Aktiva Tertimbang Menurut Risiko (ATMR). Capital Adequacy Ratio (CAR) yaitu ratio minimum perbandingan antara modal risiko dengan aktiva yang mengandung risiko (Abdullah dan Tantri 2013). Nilai Capital Adequacy Ratio (CAR) yang tinggi maka akan meningkatkan kemampuan dalam hal finansial bank termasuk mengantisipasi kerugian yang timbul dari aktivitas penyaluran kredit perbankan (Febrianto dan Muid 2013). Semakin tinggi Capital Adequacy Ratio (CAR) maka semakin besar pula sumber daya finansial yang dapat digunakan untuk keperluan pengembangan usaha dan mengantisipasi potensi kerugian yang diakibatkan oleh penyaluran kredit (Oktaviani 2012).

Non Performing Loan (NPL) yaitu risiko kredit terbesar yang dihadapi perbankan (Putra dan Rustariyuni, 2015). Non Performing Loan (NPL) memperlihatkan kemampuan manajemen perbankan dalam mengatasi kredit bermasalah (Amaliawiati 2014). Semakin tinggi NPL, mengakibatkan risiko kredit yang dihadapi oleh perbankan semakin tinggi (Buchory 2014). Tingginya Non Performing Loan (NPL) merupakan salah satu sebab sulitnya suatu bank untuk memberikan pinjaman.

Menurut (Buchory 2014), Non Performing Loan (NPL) adalah kredit yang kategori kolektibilitasnya diluar kolektibilitas kredit lancar dan kredit dalam perhatian khusus. Non Performing Loan (NPL) merupakan rasio yang digunakan untuk mengukur kemampuan bank dalam meng-cover risiko kegagalan pengembalian kredit oleh debitur (Panggalih 2015). Non Performing Loan (NPL) yaitu persentase jumlah kredit bermasalah dengan kriteria kurang 
lancar, diragukan dan macet terhadap total kredit yang disalurkan bank (Lestari dan Widyawati 2014). Menurut PBI 14/22/PBI/2012 menyatakan bahwa besarnya NPL pada bank di Indonesia adalah sebesar kurang dari 5 persen. Apabila NPL melebihi batas maka bank tersebut dinyatakan tidak sehat karena banyaknya jumlah kredit bermasalah pada bank tersebut.

Sertifikat Bank Indonesia (SBI) adalah surat berharga atas unjuk dalam rupiah yang diterbitkan oleh Bank Indonesia sebagai pengakuan hutang jangka waktu pendek dengan sistem diskonto (Panggalih 2015). Bank dapat memperoleh keuntungan lain (suku bunga) dari investasi surat-surat berharga dengan pertimbangan opportunity cost (risiko menyalurkan kredit) tersebut. Investasi tersebut dapat berupa Sertifikat Bank Indonesia (SBI) yang memiliki tingkat risiko yang rendah dan tingkat likuiditas tinggi karena merupakan investasi jangka pendek (Panggalih 2015). Tingkat bunga adalah harga atau biaya yang dibayarkan untuk dana pinjaman tersebut (Mishkin 2011). Menurut (Wulandari 2013) Sertifikat Bank Indonesia (SBI) merupakan instrumen yang menawarkan return yang cukup kompetitif serta bebas risiko (risk free). Tingkat bunga SBI ditentukan oleh mekanisme pasar berdasarkan sistem lelang. SBI diterbitkan oleh BI sebagai salah satu piranti Operasi Pasar Terbuka, kegiatan transaksi di pasar uang yang dilakukan oleh BI dengan bank dan pihak lain dalam rangka pengendalian moneter (Oktaviani 2012).

Kredit diartikan sebagai kepercayaan, begitu pula dalam bahasa latin kredit berarti Credere yang artinya kepercayaan (Abdullah dan Tantri 2013). Berdasarkan Undang-Undang Nomor 10 tahun 1998, kredit adalah penyediaan uang atau tagihan yang dipersamakan dengan itu, berdasarkan persetujuan atau kesepakatan pinjam meminjam antara bank dengan pihak lain yang diwajibkan pihak peminjam untuk melunasi hutangnya setelah jangka waktu tertentu dengan jumlah bunga.

Penelitian mengenai faktor-faktor yang memengaruhi penyaluran kredit perbankan pada Bank Umum telah diteliti oleh (Oktaviani 2012; Febrianto dan Muid 2013; Sari 2013; Saryadi 2013; dan Apsari 2015). Variabel independen yang digunakan adalah DPK, ROA, CAR, NPL, LDR, BOPO, KAP dan jumlah SBI. Semua peneliti menggunakan alat analisis regresi linear berganda. Hasil penelitan (Oktaviani 2012), menunjukkan bahwa DPK dan CAR berpengaruh positif signifikan terhadap penyaluran kredit, sedangkan SBI berpengaruh negatif signifikan terhadap penyaluran kredit perbankan. ROA dan NPL tidak berpengaruh terhadap kredit perbankan. Penelitian (Febrianto dan Muid 2013) diperoleh hasil bahwa DPK dan LDR berpengaruh positif signifikan sedangkan NPL, CAR, ROA, dan BOPO tidak berpengaruh signifikan terhadap jumlah penyaluran kredit perbankan. (Sari 2013) memperoleh hasil bahwa secara parsial variabel DPK berpengaruh positif tidak signifikan, CAR dan NPL berpengaruh negatif signifikan dan BI Rate berpengaruh positif signifikan terhadap penyaluran kredit Bank Umum di Indonesia. Hasil penelitian (Saryadi 2013) menunjukkan bahwa profit, LDR, NPL, DPK tidak berpengaruh signifikan. KAP dan ROA berpengaruh positif signifikan terhadap penyaluran kredit perbankan. Sedangkan hasil penelitian (Apsari 2015) menunjukkan bahwa DPK berpengaruh positif signifikan, CAR berpengaruh negatif tidak signifikan, NPL berpengaruh negatif signifikan, ROA dan Suku bunga SBI berpengaruh positif tidak signifikan terhadap penyaluran kredit perbankan.

(Yoga dan Yuliarmi 2013; Putra dan Rustariyuni 2015; Aljufri dan Onasis 2015) melakukan penelitian tentang faktor-faktor yang memengaruhi penyaluran kredit BPR. Variabel independen yang digunakan adalah DPK, PDRB, SBK, dan NPL. Alat analisis yang digunakan adalah analisis regresi linear berganda. Hasil penelitian (Yoga dan Yuliarmi 2013) menunjukkan bahwa NPL tidak berpengaruh signifikan terhadap penyaluran kredit. Penelitian (Putra dan Rustariyuni 2015) menunjukkan bahwa adalah DPK, BI rate dan NPL berpengaruh 
positif dan signifikan terhadap penyaluran kredit. Sedangkan hasil penelitian (Aljufri dan Onasis 2015) menunjukkan bahwa NPL dan BOPO berpengaruh negatif siginifikan terhadap jumlah kredit. LDR berpengaruh signifikan dan positif terhadap jumlah kredit yang disalurkan, namun untuk CAR dan ROA tidak berpengaruh terhadap jumlah kredit yang disalurkan.

(Putra dan Wirathi 2014) melakukan penelitian mengenai faktor-faktor yang memengaruhi penyaluran kredit UMKM di bank Umum Provinsi Bali periode 2004-2013. Variabel independen yang digunakan adalah LDR, BI rate, CAR dan NPL. Alat analisis yang digunakan adalah analisis regresi linear berganda. Hasil penelitian menunjukkan bahwa BI rate dan NPL berpengaruh negatif signifikan. LDR berpengaruh positif signifikan sedangkan CAR tidak berpengaruh signifikan terhadap penyaluran kredit.

Penelitian tentang pengaruh modal terhadap penyaluran kredit bank. Variabel yang digunakan dalam penelitian ini adalah modal bank (Bridges et al. 2014). Alat analisis yang digunakan adalah regresi data panel. Hasil penelitian menunjukkan bahwa kebutuhan modal mempengaruhi pinjaman dengan tanggapan yang heterogen di berbagai sektor ekonomi dan pertumbuhan kredit untuk real komersial nyata.

(Panggalih 2015) melakukan penelitian tentang Analisis Pengaruh DPK, NPL, Suku Bunga Sertifikat Bank Indonesia (SBI), dan Suku Bunga KUR terhadap penyaluran Kredit Usaha Rakyat (KUR) (Studi Pada PT Bank Rakyat Indonesia (Persero) Tbk. Periode Januari 2012 - Agustus 2014). Alat analisis yang digunakan adalah analisis regresi linear berganda. Hasil penelitian menunjukkan bahwa DPK, NPL, SBI berpengaruh signifikan sedangkan suku bunga KUR tidak berpengaruh signifikan terhadap penyaluran kredit.

Penelitian ini akan menguji hipotesis faktor-faktor yang mempengaruhi penyaluran kredit Bank Umum Milik negara. Capital Adequacy Ratio (CAR) memperlihatkan seberapa jauh seluruh aktva bank yang mengandung risiko ikut dibiayai dari dana modal sendiri bank disamping memperoleh dana dari sumber-sumber di luar Bank (Riyadi 2017). Semakin tinggi CAR maka akan mempengaruhi jumlah dana yang akan disalurkan untuk kredit sehinga kemampuan Bank dalam menyalurkan kreditnya akan berkurang (Sari 2013).

Non Performing Loan (NPL) adalah perbandingan antara jumlah kredit yang diberikan dengan tingkat kolektibilitas 3 sampai dengan 5 dibandingkan dengan total kredit yang diberikan oleh bank (Kasmir 2016). Semakin besar tingkat Non Performing Loan (NPL) ini menunjukkan bahwa bank tersebut tidak profesional dalam pengelolaan kreditnya, sekaligus memberikan indikasi bahwa tingkat risiko atas pemberian kredit pada bank tersebut cukup tinggi searah dengan tingginya NPL (Riyadi 2017). Berdasarkan hasil penelitian yang dilakukan oleh (Apsari 2015; Aljufri dan Onasis 2015; Putra dan Wirathi 2014; Sari 2013) menunjukkan bahwa NPL berpengaruh negatif signifikan terhadap penyaluran kredit.

SBI adalah surat berharga atas unjuk dalam rupiah yang diterbitkan dengan sistem diskonto oleh Bank Indonesia, sebagai pengakuan atas utang jangka pendek (Kasmir 2016). Kegiatan dalam manajemen perbankan dalam meminimalkan risiko kredit macet ialah mencari alternatif investasi yang lebih baik yaitu slah satunya melakukan penempatan dana pada SBI yang memiliki tingkat risiko paling rendah (Oktaviani 2012). Hal ini memberikan pengaruh terhadap perekonomian Indonesia. Suku bunga SBI meningkat maka penyaluran kredit bank akan meningkat (Panggalih 2015).

Penelitian (Oktaviani 2012; Sari 2013) memberikan hasil bahwa kemampuan variabel independen dalam menerangkan variasi perubahan variabel dependen lebih dari 97,8 persen menjelaskan variabel dependen. Sisanya diterangkan oleh faktor-faktor lain di luar model regresi yang dianalisis. Hal ini menggambarkan bahwa variabel independen yang dipakai dalam penelitian mampu menjelaskan variabel dependen yaitu penyaluran kredit.

$\mathrm{H}_{1}$ : CAR berpengaruh negatif signifikan terhadap penyaluran kredit perbankan. 
$\mathrm{H}_{2}$ : NPL berpengaruh negatif signifikan terhadap penyaluran kredit perbankan.

$\mathrm{H}_{3}$ : SBI berpengaruh positif signifikan terhadap penyaluran kredit perbankan.

$\mathrm{H}_{4}$ : Model yang dipakai dalam penelitian ini layak untuk menjelaskan penyaluran kredit perbankan.

Berdasarkan kajian teori dan diperkuat penelitian terdahulu diduga bahwa faktor- faktor yang memengaruhi penyaluran kredit yaitu Capital Adequacy Ratio (CAR), Non Performing Loan (NPL), dan Suku Bunga Sertifikat Bank Indonesia (SBI) berpengaruh terhadap penyaluran kredit.

\section{Metode Penelitian}

Penelitian ini bertujuan untuk mengetahui pengaruh variabel Capital Adequacy Ratio, Non Performing Loan, dan Suku Bunga Sertifikat Bank Indonesia terhadap penyaluran kredit. Data yang digunakan adalah data sekunder yaitu berupa data laporan keuangan Bank BUMN periode 2015 sampai dengan 2017. Sumber data diperoleh dari website resmi Bank Indonesia dan website resmi Otoritas Jasa keuangan.

Populasi yang digunakan dalam penelitian ini adalah laporan kinerja keuangan Bank BUMN periode 2015 - 2017. Teknik pengambilan sampel yang digunakan dalam penelitian ini adalah non probability sampling dengan metode pemilihan sampling jenuh yang merupakan teknik penentuan sampel semua anggota populasi digunakan sebagai sampel (Sugiyono 2017).

Variabel yang digunakan dalam penelitian ini dibedakan menjadi dua kategori, yaitu variabel independen dan variabel dependen. Variabel independen merupakan variabel yang mempengaruhi atau yang menjadi sebab perubahannya atau timbulnya variabel dependen. Dalam penelitian ini yang merupakan variabel independen adalah Capital Adequacy Ratio (CAR), Non Performing Loan atau (NPL), dan Suku Bunga Sertifikat Indonesia (SBI). Variabel dependen merupakan variabel yang dipengaruhi atau yang menjadi akibat, karena adanya variabel independen. Dalam penelitian ini sebagai variabel dependen adalah penyaluran kredit.

Metode analisis data yang digunakan dalam penelitian ini adalah metode analisis data kuantitatif. Metode analisis data kuantitatif bertujuan untuk mencari uraian secara menyeluruh dan komprehensif berdasarkan data empiris (Sugiyono 2017). Proses model regresi menggunakan software Eviews 8.0 untuk mendapatkan hasil yang lebih akurat.

\section{Hasil Penelitian dan Pembahasan}

Deskripsi variabel penelitian ini menjelaskan tentang kondisi variabel independen yaitu Capital Adequacy Ratio, Non Performing Loan), dan suku bunga SBI), serta variabel dependen yaitu Penyaluran kredit. Analisis statistik deskriptif digunakan untuk menganalisa, mendeskripsikan serta menggambarkan karakteristik variabel-variabel yang digunakan dalam penelitian ini. Variabel bebas (independen) yang digunakan terdiri dari Capital Adequacy Ratio (CAR), Non Performing Loan (NPL), Suku bunga Sertifikat Bank Indonesi (SBI) dan Variabel terikat (Dependen) yaitu Penyaluran Kredit.

Berdasarkan Tabel 1, dapat dilihat hasil output statistik bahwa nilai maksimum kredit mencapai 558.446,7 rupiah, nilai terendah yaitu sebesar 79.167,94 rupiah, dan rata-rata nilai kredit yaitu sebesar 312.919,2 rupiah. Rasio CAR mencapai nilai maksimum sebesar 20,59 persen, nilai terendah yaitu sebesar 14,33 persen dan rata-rata nilai CAR yaitu 16,92 persen. Rasio NPL mencapai nilai maksimum sebesar 5,01 persen, dengan nilai terendah yaitu sebesar 1,55 persen dan nilai rata-rata NPL yaitu sebesar 2,69 persen. SBI 
INOBIS: Jurnal Inovasi Bisnis dan Manajemen Indonesia

Volume 03, Nomor 01, Bulan Desember 2019

Sita Nurmalia Adha, Hedwigis Esti Riwayati

mencapai nilai maksimum sebesar 7,21 persen sedangkan nilai terendah yaitu 4,86 persen dan rata-rata nilai SBI sebesar 6,63 persen.

Tabel 1 Statistik Deskriptif Variabel Penelitian

\begin{tabular}{|l|c|c|c|c|}
\hline Indikator & KREDIT & CAR & NPL & \multicolumn{1}{c|}{ SBI } \\
\hline Mean & 312919.2 & 16.92854 & 2.691458 & 6.633333 \\
\hline Median & 324481.0 & 16.78500 & 2.210000 & 6.890000 \\
\hline Maximum & 558446.7 & 20.59000 & 5.010000 & 7.210000 \\
\hline Minimum & 79167.94 & 14.33000 & 1.550000 & 4.860000 \\
\hline Std. Dev. & 154674.9 & 1.602846 & 1.141321 & 0.738594 \\
\hline Skewness & -0.162688 & 0.623037 & 1.016701 & -1.588298 \\
\hline Kurtosis & 1.600600 & 2.807569 & 2.448963 & 3.994169 \\
\hline & & & & \\
\hline Jarque-Bera & 4.128380 & 3.179461 & 8.876730 & 22.15826 \\
\hline Probability & 0.126921 & 0.203981 & 0.011815 & 0.000015 \\
\hline & & & & \\
\hline Sum & 15020121 & 812.5700 & 129.1900 & 318.4000 \\
\hline Sum Sq. Dev. & $1.12 \mathrm{E}+12$ & 120.7484 & 61.22280 & 25.63947 \\
\hline \multicolumn{2}{|r|}{} & 48 & & \\
\hline Observations & 48 & 48 & 48 \\
\hline
\end{tabular}

Sumber: Output SPSS

Analisis data merupakan hal yang penting dalam suatu penelitian agar dapat memecahkan suatu permasalahan yang akan diteliti. Teknis analisis data yang digunakan berupa data panel. Data panel atau biasa disebut pooled data adalah gabungan data cross section dan time series. Penelitian ini menggunakan data panel dikarenakan objek penelitiannya terdiri dari 4 bank umum di Bursa Efek Indonesia dalam bentuk laporan triwulan. Metode yang digunakan dalam penenlitian ini adalah metode regresi data panel. Pada penelitian ini, peneliti melakukan pengolahan data dan perhitungan dengan menggunakan bantuan software alat pengolahan data kuantitatif berupa program Microsoft Excel versi 2010 dan Eviews 8.0. Perlu dilakukan beberapa pengujian dalam memilih model yang tepat bagi penelitian ini. Pengujian dilakukan agar dapat memastikan model common, fixed, atau random yang tepat dalam penelitian ini. Pengujian yang harus dilakukan yaitu uji chow dan uji hausman.

1. Uji Chow

Uji chow dilakukan untuk mengetahui model mana yang tepat antara common effect atau fixed effect. Pengujian ini dilakukan dengan menggunakan uji statistik $\mathrm{F}$ atau chi-square. Pengujian ini dilakukan dengan ketentuan.

1) Jika nilai $\mathrm{F}$ atau chi-square $>0,05$, maka ketentuanyya model mengikuti common effect.

2) Jika nilai $\mathrm{F}$ atau chi-square $<0,05$, maka ketentuannya model mengikuti fixed effect.

Berdasarkan hasil uji chow (Tabel 2) bahwa nilai probabilitas F-test sebesar 0,0000 lebih kecil dari 0,05 . Sesuai syarat yang ada maka model yang cocok yaitu fixed effect model. Dengan demikian dapat ditarik kesimpulan bahwa model fixed effect lebih layak untuk digunakan dalam mengestimasi data panel dibandingkan common effect.

\section{Tabel 2 Hasil Uji Chow}


INOBIS: Jurnal Inovasi Bisnis dan Manajemen Indonesia

Volume 03, Nomor 01, Bulan Desember 2019

Sita Nurmalia Adha, Hedwigis Esti Riwayati

Effects Test

Cross-section F

Cross-section Chi-square

Sumber: Output Eviews

\begin{tabular}{rrr} 
Statistic & d.f. & Prob. \\
\hline 135.869972 & $(3,41)$ & 0.0000 \\
114.843920 & 3 & 0.0000 \\
\hline
\end{tabular}

2. Uji Hausman

Uji hausman dilakukan untuk mengetahui model mana yang lebih cocok antara fixed effect atau random effect. Pengujian ini dilakukan dengan ketentuan sebagai berikut:

1) Jika nilai $\mathrm{F}>0,05$, maka ketentuannya model mengikuti random effect.

2) Jiks nilis $\mathrm{F}<0,05$, maka ketentuannya model mengikuti fixed effect.

\section{Tabel 3 Hasil Uji Hausman}

Test Summary

Cross-section random

Sumber: Output Eviews

\begin{tabular}{rcr} 
Chi-Sq. Statistic & Chi-Sq. d.f. & Prob. \\
\hline 6.632081 & 3 & 0.0846
\end{tabular}

Tabel 3 menunjukkan bahwa hasil uji hausman nilai probabilitas cross- section random effect sebesar 0,0846 lebih besar dari 0,05. Dengan demikian model yang cocok yang digunakan adalah modelrandom effect. Dengan demikian dapat ditarik kesimpulan bahwa model random effect lebih baik digunakan dalam penelitian ini dari pada model fixed effect.

Dari hasil kedua pengujian yang telah dilakukan dalam penelitian ini mendapatkan hasil yang sama dari dua pengujian tersebut.

Tabel 4 Hasil Pemilihan Model Regresi Data Panel

\begin{tabular}{|c|c|c|}
\hline Metode & Pengujian & Hasil \\
\hline Chow Test & Common Effect vs Fixed Effect & Fixed Effect \\
\hline Hausman Test & Fixed Effect vs Random Effect & Random Effect \\
\hline Lagrange Multiplier Test & Common Effect vs Random Effect & - \\
\hline
\end{tabular}

Sumber: Output Eviews

Berdasarkan uji chow dan uji Hausman didapatkan hasil yang berbeda yaitu uji chow diperoleh hasilnya yaitu fixed effect sedangkan pada uji hausman diperoleh hasilnya yaitu random effect. Dengan demikian model yang pantas digunakan dalam penelitian ini adalah random effect. Pengujian lagrange multiplier test tidak digunakan karena pada pengujian uji chow hasil yang didapat adalah fixed effect. Sedangkan dalam uji LM adalah pengujian untuk menentukan lebih baik menggunakan model common effect atau random effect. . 
INOBIS: Jurnal Inovasi Bisnis dan Manajemen Indonesia

Volume 03, Nomor 01, Bulan Desember 2019

Sita Nurmalia Adha, Hedwigis Esti Riwayati

Analisis regresi data panel bertujuan untuk melihat ada atau tidaknya pengaruh variabel CAR, NPL, dan suku bunga SBI terhadap penyaluran kredit. Model yang digunakan dalam analisis adalah model random effect.

Tabel 5 Hasil Regresi Data Panel Random Model.

Total panel (balanced) observations: 48

\begin{tabular}{crrrr}
\cline { 2 - 5 } Variable & Coefficient & Std. Error & t-Statistic & Prob. \\
\cline { 2 - 5 } LOG(CAR) & 1.367216 & 0.176668 & 7.738906 & 0.0000 \\
LOG(NPL) & -0.439598 & 0.089407 & -4.916804 & 0.0000 \\
LOG(SBI) & 0.738777 & 0.089812 & 8.225818 & 0.0000 \\
C & 7.636715 & 0.512523 & 14.90024 & 0.0000
\end{tabular}

Sumber: Output Eviews

Berdasarkan hasil pengolahan data dengan data panel, diperoleh Capital Adequacy Ratio (CAR) secara parsial memiliki pengaruh positif signifikan terhadap penyaluran kredit. Koefisien regresi variabel Capital Adequacy Ratio (CAR) memiliki arah positif, artinya setiap kenaikan 1 (satu) persen besarnya CAR, maka akan mengakibatkan peningkatan pada penyaluran kredit. Capital Adequacy Ratio (CAR) merupakan rasio kewajiban pemenuhan modal minimum yang harus dimiliki oleh bank. Pada dasarnya CAR suatu bank berdampak negatif terhadap penyaluran kredit. Tingginya CAR pada sebuah bank akan mengurangi penyaluran kredit dengan kata lain CAR yang tinggi berpengaruh terhadap jumlah dana yang akan disalurkan untuk kredit dan berdampak pada kemampuan bank dalam menyalurkan kredit berkurang. CAR dapat mengatasi risiko kredit, oleh sebab itu cadangan yang digunakan untuk ekspansi kredit akan berkurang sehingga akan mengurangi kegiatan penyaluran kredit.

Pada penelitian ini CAR dapat meningkatkan penyaluran kredit bank. Semakin tinggi CAR semakin baik kondisi sebuah bank (Ambarwati 2010). Semakin tinggi CAR maka akan meningkatkan kemampuan dalam hal finansial bank termasuk mengantisipasi kerugian yang timbul dari aktivitas penyaluran kredit. Tingginya risiko kecukupan modal bank yang berhasil dihimpun oleh Bank BUMN mampu memberikan tambahan modal bagi Bank BUMN dalam menyalurkan kreditnya. CAR meningkatkan kepercayaan diri perbankan dalam menyalurkan kredit. Maka CAR dianggap memiliki pengaruh yang signifikan, karena semakin besar CAR maka modal Bank yang digunakan untuk menghasilkan aktiva dalam bentuk kredit yang disalurkan juga semakin besar. Penelitian ini didukung oleh hasil penelitian yang dilakukan oleh (Oktaviani 2012) yang mendapatkan hasil bahwa Capital Adequacy Ratio (CAR) berpengaruh positif signifikan terhadap penyaluran kredit.

Variabel Non Performing Loan (NPL) secara parsial berpengaruh negatif signifikan terhadap penyaluran kredit. Koefisien regresi Non Performing Loan (NPL) memiliki arah negatif, artinya setiap kenaikan 1 persen besarnya NPL, maka akan mengakibatkan penurunan pada penyaluran kredit. Non Performing Loan (NPL) merupakan rasio yang digunakan untuk mengukur kemampuan bank dalam meng-cover risiko kegagalan pengembalian kredit. Rendahnya jumlah kredit yang bermasalah mengakibatkan dana yang disalurkan untuk penyaluran kredit semakin meningkat, mengingat keadaan kredit bermasalah merupakan salah satu hambatan dalam penyaluran kredit di Indonesia. Dalam penenlitian ini NPL memiliki pengaruh negatif signifikan terhadap penyaluran kredit perbankan, hal ini dikarenakan banyaknya jumlah kredit bermasalah menyebabkan sedikitnya dana yang dapat disalurkan untuk melakukan kredit di masa yang akan datang. 
Semakin tinggi NPL maka semakin besar pula risiko kredit yang ditanggung oleh bank dan semakin tinggi NPL akan menurunkan jumlah kredit yang disalurkan. Penelitian ini didukung oleh hasil penelitian yang dilakukan oleh (Aljufri dan Onasis 2015; Apsari 2015; Putra dan Wirathi 2014; Sari 2013) yang mendapatkan hasil bahwa Non Performing Loan berpengaruh negatif signifikan terhadap penyaluran kredit.

Suku bunga sertifikat bank indonesia (SBI) secara parsial memiliki pengaruh positif signifikan terhadap penyaluran kredit. Koefisien regresi suku bunga sertifikat bank indonesia (SBI) memiliki arah positif, artinya setiap kenaikan 1 (satu) persen besarnya suku bunga SBI, maka akan mengakibatkan peningkatan pada penyaluran kredit. SBI merupakan surat berharga dalam mata uang Rupiah yang diterbitkan oleh Bank Indonesia sebagai pengakuan utang berjangka waktu pendek. Pada dasarnya suku bunga SBI berdampak negatif terhadap penyaluran kredit. Suku bunga SBI yang tinggi akan membuat perbankan betah menempatkan dananya di SBI ketimbang melakukan penylaluran kredit karena banyak yang menganggap SBI sebagai salah satu instrumen yang menarik, sehingga kegiatan penyaluran kredit akan menurun.

Pada penelitian ini suku bunga SBI meningkatkan penyaluran kredit bank. Tingginya suku bunga SBI dapat menyebabkan masyarakat memindahkan dananya ke deposito, karena kenaikan suku bunga SBI akan diikuti oleh Bank Umum untuk meningkatkan suku bunga simpanan. Masyarakat akan lebih tertarik menyimpan dananya ke deposito. Dana pihak ketiga bank tersebut akan bertambah banyak sehingga kemampuan Bank BUMN dalam melakukan penyaluran kredit akan terus meningkat. Penelitian ini didukung oleh hasil penelitian yang dilakukan (Apsari 2015; Panggalih 2015) yang mendapatkan hasil bahwa suku bunga Sertifikat Bank Indonesia (SBI) berpengaruh positif signifikan terhadap penyaluran kredit.

Hasil uji kelayakan model (uji F) dalam penelitian ini bahwa variabel Capital Adequacy Ratio (CAR), Non Performing Loan (NPL) dan suku bunga Sertifikat Bank Indonesia (SBI) layak untuk menjelaskan penyaluran kredit perbankan pada Bank BUMN periode 2015 hingga 2017. Nilai Adjusted R-squared diperoleh sebesar 0,55 maka variabel Capital Adequacy Ratio (CAR), Non Performing Loan (NPL) dan suku bunga Sertifikat Bank Indonesia (SBI) dapat menjelaskan penyaluran kredit perbankan sebesar 55 persen dan sisanya 45 persen dijelaskan oleh variabel lain di luar penelitian ini.

\section{Kesimpulan dan Rekomendasi}

Capital Adequacy Ratio (CAR) berpengaruh positif signifikan terhadap variabel penyaluran kredit pada Bank BUMN periode 2015 - 2017. Hal tersebut menunjukkan bahwa semakin besar CAR maka modal Bank yang digunakan untuk menghasilkan aktiva dalam bentuk kredit yang disalurkan semakin besar. Variabel Non Performing Loan (NPL) berpengaruh negatif signifikan terhadap variabel penyaluran kredit pada Bank BUMN periode 2015 - 2017. Semakin tinggi NPL menyebabkan sedikitnya dana yang akan disalurkan untuk penyaluraan kredit dimasa yang akan datang. Suku bunga Sertifikat Bank Indonesia (SBI) berpengaruh positif signifikan terhadap variabel penyaluran kredit pada Bank BUMN periode 2015 - 2017. Tingginya suku bunga SBI dapat menyebabkan masyarakat memindahkan danaya ke deposito, karena kenaikan suku bunga SBI akan diikuti oleh Bankbank umum untuk meningkatkan suku bunga simpanan sehingga masyarakat akan lebih tertarik menyimpan dananya ke deposito yang menyebabkan DPK akan bertambah sehingga kemampuan bank BUMN dalam melakukan penyaluran kredit akan terus meningkat. Variabel Capital Adequacy Ratio, Non Performing Loan, dan suku bunga Sertifikat Bank Indonesia sebagai variabel independen dapat menjelaskan penyaluran kredit sebesar 55,1323 persen 
dan sisanya 44,8677 dijelaskan oleh variabel lain faktor makroekonomi (inflasi dan pertumbuhan ekonomi) yang tidak diteliti dalam penelitian ini.

Saran yang dapat diberikan berdasarkan hasil penelitian ini sebagai berikut: 1) agar kinerja Bank BUMN menjadi optimal harus b is a mengurangi CAR dan dana yang ada digunakan untuk investasi atau disalurkan untuk kredit;2) Bank BUMN menetapkan suku bunga yang rendah agar penyaluran kredit bank akan terus meningkat; 3) diharapkan dapat memberikan kontribusi yang baik serta dapat mengembangkan wawasan masyarakat tentang penyaluran kredit bank; 4) Peneliti selanjutnya dengan topik yang sejenis diharapkan dapat menambah variabel bebas lainnya yang diperkirakan berpengaruh terhadap penyaluran kredit seperti DPK, LDR dan variabel makro seperti inflasi.

\section{Daftar Pustaka}

Abdullah, T., dan Tantri, F. 2013. Bank dan Lembaga Keuangan. Jakarta: PT Raja Grafindo Persada.

Aljufri, F. O., dan Onasis, D. 2015. Pengaruh Tingkat Kesehatan Keuangan Terhadap Penyaluran Kredit Pada PT Bpr Cempaka Mitra Nagori Kuansing Di Taluk Kuantan. Jurnal Ilmiah Ekonomi dan Bisnis. Vol 12 No. 2.

Amaliawiati, L. 2014. Analysis the Influence of Effectiveness Intermediation Function Banks on Efficiency Bank (Case Study: Conventional Banks and Islamic Banks in Indonesia). International Journal of Science and Research (IJSR). Vol 3 (4).

Ambarwati, S. D. A. 2010. Manjemen Keuangan Lanjutan (Pertama). Yogyakarta: Graha Ilmu.

Apsari, B. A. 2015. Analisis Pengaruh DPK, CAR, NPL, ROA dan Suku Bunga SBI Terhadap Kredit Perbankan (Studi kasus pada Bank Umum Yang Terdaftar Di Bursa Efek Indonesia Periode 2009 - 2013). Jurnal Ilmiah Ekonomi dan Bisnis.

Bridges, J. et al. 2014. The Impact Of Capital Requirements On Bank Lending. Journal of Economic Literature No. 486.

Buchory, H. A. 2014. Analysis Of The Effect Of Capital, Credit Risk And Profitability to Implementation Banking Intermediation Function (Study On Regional Development Bank All Over Indonesia Year 2012). International Journal of Business, Economics and Law. Vol. 4 (1).

Febrianto, D. F., dan Muid, D. 2013. Analisis pengaruh dana pihak ketiga, ldr, npl, car, roa, dan bopo terhadap jumlah penyaluran kredit. Diponegoro Journal Of Accounting .Vol. 2 (4).

Kasmir. 2016. Bank dan Lembaga Keuangan Lainnya. Jakarta: PT Raja Grafindo Persada.

Lestari, S. M., dan Widyawati, N. 2014. Faktor-Faktor yang Mempengaruhi Return On Asset pada Perusahaan Perbankan Di BEI. Jurnal Ilmu \& Riset Manajemen. Vol. 3 (3).

Mishkin, F.S. 2008. The economic of mone, banking and financial markets. $8^{\text {th }}$ Edition. Pearson Education.

Oktaviani, I. R. D. P. 2012. Pengaruh DPK, ROA, CAR, NPl, dan Jumlah SBI Terhadap Penyaluran Kredit Perbankan (Studi Pada Bank Umum Go Public di Indonesia Periode 2008-2011). Diponegoro Journal Of Management. Vol. 1 (2).

Panggalih, D. N. C. 2015. Analisis Pengaruh Dana Pihak Ketiga (DPK), Non Performing Loan (NPL), Suku Bunga Sertifikat Bank Indonesia (SBI), dan Suku Bunga Kur Terhadap Penyaluran Kredit Usaha Rakyat (KUR). Jurnal Ilmiah Ekonomi dan Bisnis. 
Putra, I. G. A. N. B. G., dan Wirathi, I. G. A. P. 2014. Pengaruh LDR, BI Rate, CAR, NPL Terhadap Penyaluran Kredit UMKM di Bank Umum Provinsi Bali Periode 2004.I2013. E-Jurnal Ekonomi Pembangunan Universitas Udayana. Vol. 3 (12).

Putra, I. G. O. P., dan Rustariyuni, S. D. 2015. Pengaruh Dpk, Bi Rate, dan Npl Terhadap Penyaluran Kredit Modal Kerja pada Bpr Di Provinsi Bali Tahun 2009-2014. E-Jurnal Ekonomi Pembangunan Universitas Udayana .Vol. 4 (5).

Riyadi, S. 2017. Manajemen Perbankan Indonesia. Depok: PT Rajagrafindo Persada.

Sari, G. N. 2013. Faktor-Faktor yang Mempengaruhi Penyaluran Kredit Bank Umum Di Indonesia (Periode 2008.1 - 2012.2), Jurnal EMBA Vol.1 (3).

Saryadi. 2013. Faktor-faktor yang berpengaruh terhadap Penyaluran Kredit Perbankan (Studi pada Bank Umum Swasta Nasional Devisa). Jurnal Administrasi Bisnis. Vol. 2 (1).

Sugiyono. 2017. Metode Penelitian Kuantitatif Kualitatif dan $R \&$ D. Bandung: Alfabeta.

Wulandari, F. 2013. Faktor-faktor yang mempengaruhi Penyaluran Kredit pada Bank Umum yang telah go public periode tahun 2011-2013. Jurnal Ilmiah Ekonomi dan Bisnis.

Yoga, G. A. D. M., dan Yuliarmi, N. N. 2013. Faktor-faktor yang Mempengaruhi Penyaluran Kredit Bpr di Provinsi Bali. E-Jurnal Ekonomi Pembangunan Universitas Udayana. Vol $2(6)$ 